\title{
LV. On the electrical and chemical properties of stannic chloride; together with the bearing of the results therein obtained on the problems of electrolytic conduction and chemical action.-Part I. Experimental observations. Part II. Theoretical considerations
}

\section{Ward Coldridge B.A.}

To cite this article: Ward Coldridge B.A. (1890) LV. On the electrical and chemical properties of stannic chloride; together with the bearing of the results therein obtained on the problems of electrolytic conduction and chemical action.-Part I. Experimental observations. Part II. Theoretical considerations, Philosophical Magazine Series 5, 29:181, 480-490, DOI: 10.1080/14786449008619972

To link to this article: http://dx.doi.org/10.1080/14786449008619972

Published online: 08 May 2009.

Submit your article to this journal $\llbracket$

Џll Article views: 2 
expressly state, that also in this case double layers are formed on the drops, whose negative electricity comes from the electrolyte. The supply of this electricity depends therefore on the conductivity of the electrolyte. The process can, however, no longer be a lasting one, because the secondary electrode is immediately polarized. Mr. Brown can easily convinee himself (if he has not already noticed it), that the current produced under such circumstances is much weaker than the one earlier mentioned, and that it becomes continually weaker owing to the polarization, while the other current can be kept for days at its original strength.

Finally, it follows from the theory of v. Helmboltz, that a diminishing current of opposite direction must be obtained if the secondary electrode is connected, not with the dropping mercury, but with that collecting on the bottom of the vessel. This current can also easily be observed. According to Mr. Brown's ideas, if I have correctly understood them, in this case no current whatever could be produced.

Brüder Strasse, Leipzic.

I.V. On the Electrical and Chemical Properties of Stannic Chloride; together with the Bearing of the Results therein obtained on the Problems of Electrolytic Conduction and Chemical Action.-Part I. Experimental Obserrations. Part II. Theoretical Considerations. By WARd Coldridge, B.A., Scholar of Emmanuel College, Cambridge.

[Concluded from p. 394.]

Part II.-Theoretical Considerations.

TTHE first problem that presses forward for consideration is that involved in the nonconductivity of stannic chloride.

It is a truism to write that its insulating-power is a function of its constitution; but it has hitherto been difficult, from the lack of experimental observations, to advance beyond that truism. The fact is that a column of stannic chloride, some three to four centimetres in length with a cross section of one to two square centimetres, has a resistance the lower limit of which is certainly not less than 1600 megohms. This phenomenon is not an isolated one. Other pure liquids-water, hydrochloric acid, hydrofluoric acid-are also nonconductors, but liquid hydrocyanic acid is said to be an electrolyte ; and the fused salts, of which the silver halogen compounds may be taken as typical, easily electrolyse. Wherein, then, do these liquids which are nonelectrolytes differ from those which are electrolytes? In order to progress towards a solution of this 
question a review will now be made :- of the chemical characteristics, as far as they are pertinent, of those compounds ; of the possible influence of their physical aggregation; and, lastly, of the conditions under which the power of electrolysability can be developed.

To take the liquids seriatim :-

Water is characterized by its stability and by its large heat of formation. If it could be directly oxidized to hydrogen peroxide, the change would involve a large absorption of energy,

$$
\left(\mathrm{H}_{2} \mathrm{O}, \mathrm{O}\right)=23,100 \text { cal. }
$$

Thus it is not possible for pure water to become nonhomogeneous through the formation of any peroxide: the only other way in which water could become chemically nonhomogeneous, save through the formation of molecular aggregates of varying complexity, would be by its dissociation in part into hydrogen and oxygen atoms; but this is a most remote speculative chance and a practical impossibility.

Hydrofluoric Acid is the only compound of bydrogen and fluorine. There is neither a perfluoride $\left(\mathrm{HF}_{x}\right)$ nor a subfluoride $\left(\mathrm{H}_{x} \mathrm{~F}\right)$. Moissan examined the product of the electrolysation of liquid hydrofluoric acid, rendered a conductor by the presence of dissolved potassium hydrogen fluoride, and found no evidence of such a change as

$$
\mathrm{H}_{x} \mathrm{~F}_{x}=y \mathrm{H}+\mathrm{H}_{x-y} \mathrm{~F}_{x},
$$

and established that the ions, as liberated, are simply hydrogen and fluorine.

Hydrochloric Acid is the only compound of hydrogen and chlorine. I think that no one has endeavoured to perform with liquid hydrochloric acid experiments analogons to those of Moissan's for the sake of their electrolytic importance.

Stannic Chloride in the vaporized condition can exist per-

fectly as a collection of like unit particles, molecules $\mathrm{SnCl}_{4}$

There is a lower compound, stannous chloride; but the forward change,

$$
\mathrm{SnCl}_{2}+\mathrm{Cl}_{2} \rightarrow \mathrm{SnCl}_{4}
$$

occurs with the utmost readiness. A strong presumption therefore exists against the possibility of the reverse dissociation, except at high temperatures; and there is no evidence in support of such an hypothesis.

Thus, then, water, hydrofluoric acid, hydrochloric acid, stannic chloride, agree in their chemical homogeneity.

Whilst there is the closest resemblance between the above 
nonconducting liquid acids and the conducting liquid hydrocyanic acid, in point of their physical properties, it may yet be possible to distinguish it chemically: at least it is worthy of note that

$$
(\mathrm{H}, \mathrm{C}, \mathrm{N})=-28,400 \text {, }
$$

for such a large endothermic formation is suggestive of a tendency towards instability.

The observations of Bleekrode and De La Rue (Proc. Roy. Soc. xxv. p. 323), showing its power of electrolysing, are worthy of confirmation, provided all possible precautions be taken to ensure the use of an absolutely anhydrous specimen.

In considering the phenomena presented by the fused salts, it is necessary to recall the warning given by Prof. Armstrong as to the scantiness of accurate data at the command of the inquirer into the properties of fused pure substances. Having noted this warning, a statement made by Faraday is very apposite. In the first volume of his ' Experimental Researches in Electricity,' $\$ 690$, when he is discussing the results he had obtained with fused antimony trichloride, he suggests that the conductivity he had observed "might be due perhaps to a true protochloride consisting of single proportionals (SbCl)." In a word, Faraday surmised that the fused compound was not quite homogeneous. A similar suggestion may be advanced : that silver chloride, silver iodide, selected as two of the best examples of Faraday's law of LiquidoConduction, are not homogeneous compounds in the fused state. Photo-salts - whether they be detinite compounds or mixtures is of no import-exist and are characterized by the extreme facility of their formation. Probably with more accurate information at command it will be possible to advance, in explanation of the electrolytic conduction of fused substances, this view of the imperfect homogeneity, itself supported by separate and nonelectrical considerations; and to establish as an expression of a complete uniformity that no homogeneous liquid is an electrolyte: electrolisability involves an antecedent condition of heterogeneity.

But in such a statement as that no homogeneous liquid is an electrolyte it is necessary to accurately determine the significance of the word "homogeneous." Without hesitation, for example, pure liquid stannic chloride would be spoken of as homogeneous. The statement would be accurate if the whole of the stannic chloride were composed of precisely similar unit molecules. But a view has been expounded in a profound paper by Prof. Armstrong, "On Electrolytic Conduction in relation to Molecular Composition; Valency and the Nature 
of Chemical Change; being an attempt to apply a Theory of Residual Affinity" (Proc. Roy. Soc. 1886, p. 268), that stannic chloride is not thus simply constituted, but that a condition of more complex aggregation is attained of which the particles could be represented thus :-

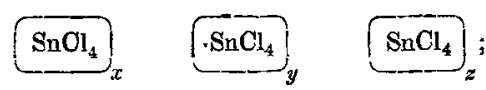

where $x, y, z$ may or may not have the same value, and are probably of considerable magnitude. He considers that these groups are built up in virtue of the "Residual Affinity" which he holds to be characteristic of the negative elements. Such a group represented graphically would appeur thus :-

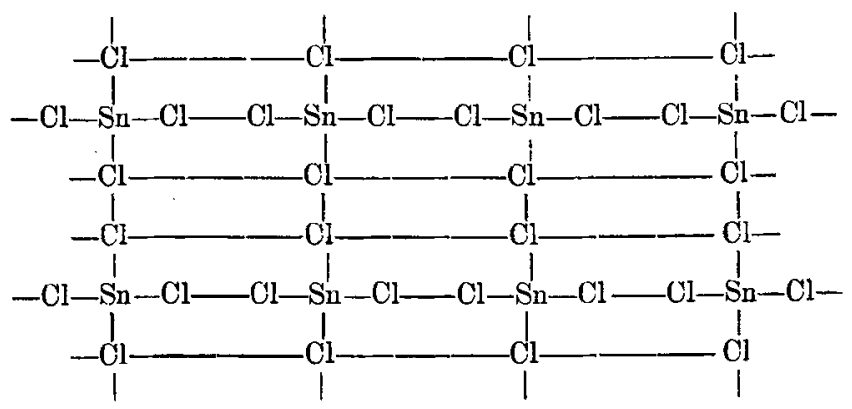

This process of construction would be continued according to the value of $x$ in $\mathrm{SnCl}_{4}$.

If a value of $x=6$ be assumed, the aggregation might be completely represented thus :-

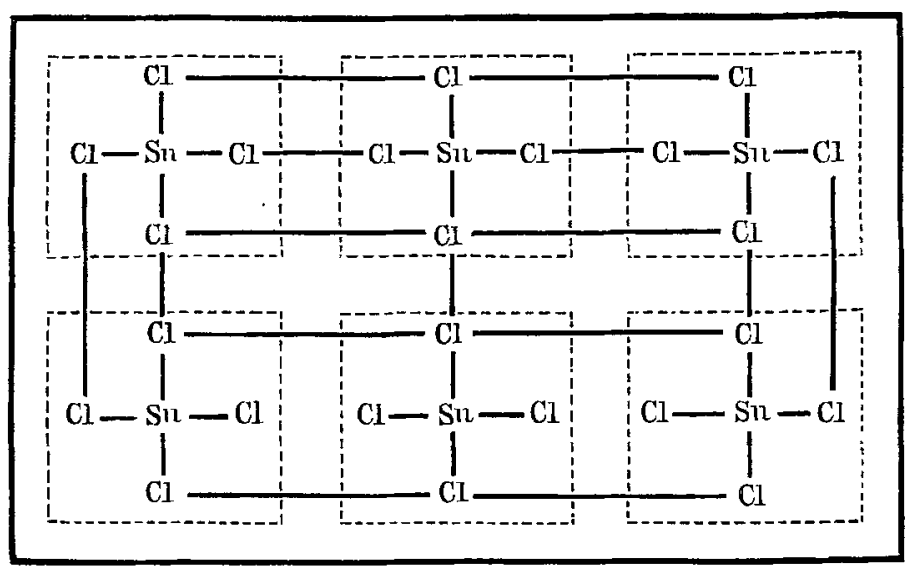


Another group might be $\left(\mathrm{SnCl}_{4}\right)_{10}$; another $\left(\mathrm{SnCl}_{4}\right)_{12}$; \&c. Then to call stannic chloride homogeneous, if thus composed of aggregates of varying complexity, is to use the term in an approximate and statistical sense, or subject to a reservation that it applies only to the ultimate molecules and not to the aggregates they form. The main purpose of this conception is the vivid realization of a condition of elephantine stability, one that shall afford a foundation for the dissociation processes which are associated with electrolytic conductivity. Thus, when Armstrong discusses the effect of water on the conductivity of the halogen acids, he submits the view that the dilution improves the conductivity by decomposing the more complex molecules; and generally he concludes, when the molecular conductivity is low, then there are big molecular aggregates. The liquid stannic chloride would consist of massive groups. This conception is fruitful, and explains many phenomena. But a simpler explanation may serve these purposes as effectively. It thus becomes of interest to consider whether it is necessary to adopt this view of the complex aggregates in the place of the simple molecular composition, whether stannic chloride is composed
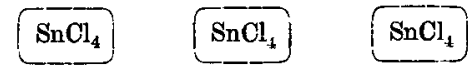

or

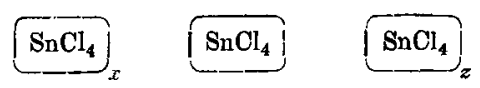

In consideration of this question, it may be advanced that stannic chloride in the gaseous condition does consist in molecules represented as in (a).

But it may be urged that some gases which have at high temperatures simple constitutions have at lower temperatures more complex ones. Thus nitrogen peroxide is " $\mathrm{NO}_{2}$ " at high, and gradually passes into " $\mathrm{N}_{2} \mathrm{O}_{4}$ " at low temperatures. Mallet has observed that hydrofluoric acid is " $\mathrm{H}_{2} \mathrm{~F}_{2}$ " just above its boiling-point. The density of acetic-acid vapour corresponds to a molecule $\mathrm{C}_{3} \mathrm{H}_{6} \mathrm{O}_{3}$ within a few degrees of its boiling-point, and then, as the temperature rises, rapidly diminishes to a density which gives the molecular weight of 60 .

Do, then, these observations lead by induction to the result that, as the vapour of $\sqrt{\mathrm{SnCl}_{4}}$ is condensed into a liquid, the molecules coming nearer and nearer coalesce into complex aggregates? If this induction be correct, then the liquid must have the constitution $\beta$. 
But the induction is based apon a fallacy. It does not follow, in the cases cited, because the densities rapidly increase, relative to hydrogen, as the temperature falls, that therefore the molecules have also become greater. For these molecular weights are determined on the assumption that Avogadro's law is applicable to these substances in a vaporized and imperfectly gasified condition. Such an assumption is untenable; it is, as Prof. J. J. Thomson emphasizes in his lectures on the Properties of Matter, more rational to conceive that the vapours do not contain equal numbers of molecules. The statements that nitrogen peroxide is " $\mathrm{N}_{2} \mathrm{O}_{4}$," that hydrofluoric acid is " $\mathrm{H}_{2} \mathrm{~F}_{2}$ ", that acetic acid is $\mathrm{C}_{3} \mathrm{H}_{6} \mathrm{O}_{3}$ ", are tainted with this fallacy; and the taint vitiates the induction that leads to the conception $(\beta)$ as the constitution of liquid stannic chloride.

Moreover, positive evidence in favour of the simpler concept is supplied by the simplicity of the results obtained for the molecular weights of solids and liquids, as determined by the extent to which they lower the fusing-points and the vapourpressure of solvents (Raoult).

On this ground the statement made as to the constitution of gaseous stannic chloride may be extended so as to include the liquid condition, provided of course a necessary degree of cohesion sufficient to account for the viscosity of the liquid be allowed between these simple material particles the molecules

$\mathrm{SnCl}_{4}$.

And, again, it may be maintained that the condition $(\alpha)$ presents a prospect of greater stability than $(\beta)$. For an inspection of the graphic representation of the group $\underbrace{}_{\mathrm{SnCl}_{4}}$ shows that, whereas according to $(\alpha)$ the chemical homogeneity is preserved solely by the attractions of the respective atoms of tin for their four respective atoms of chlorine, according to $(\beta)$ this attraction is opposed "by the straining of the chlorine atoms at the chlorine atoms of the adjoining molecules."

Thus, then, on account of the greater stability represented in the simpler view, on account of the evidence in its favour, on account of the absence of satisfactory arguments to prove the existence of the hypothetical complex aggregates, the simpler view (a) will here be taken and the stannic chloride will be considered as strictly homogeneous; sic agualiter for the other-mentioned nonconductors. And it is advanced that every substance thus strictly homogeneons is a nonelectrolyte on account of that very homogeneity. This homogeneity is a

* Horstmann, Annalen, clxviii. VI. sup. 53.

Phil. Mag. S. 5. Vol. 29. No. 181. June 1890. 
function of the chemical stability. Indeed the problem of electrolysis is at its foundation a chemical one; but at this, its foundation, the chemical problem resolves itself into an anterior physical one, namely the laws that govern the interaction, the attraction of atoms at atomic distances. "The scientific aim of the theory of electrolysis has been stated by F. Kohlrausch to consist in the reference of electrochemical phenomena to mechanical or electromechanical laws" * : herein must be the solution of the problem of chemical affinity.

To the question whether there is some physical property of pure water, pure hydrochloric acid, hydrofluoric acid, \&c. which endows them with insulating-power, and the absence or difference of degree of which in fused salts admits of conductivity no successful answer has been given, though a great variety of attempts have been made. Doubtless viscosity is a factor in the result, and Faraday's law of liquido-conduction is a statement of that fact. But the influence of viscosity is secondary rather than primary : all the electrolytes must have a degree of limpidity, and as the limpidity decreases so will the resistance increase. As examples, Kohlrausch's experiments on Silver Iodide $\dagger$, Arrhenius's investigations of the actions of Fluidity on the Conductivity of Electrolytes $\ddagger$; though these would have been improved by the use, as sole solvent, of some oily polyhydric alcohol. But limpidity, as is seen in the various nonconducting pure liquids, does not involve electrolysability. The destruction of the physical homogeneity, and generally the change of physical properties which must occur when stannic chloride is heated from $16^{\circ} \mathrm{C}$. to $112^{\circ} \mathrm{C}$., its boiling-point, has not apparently any influence, and certainly not within the limits of delicacy of my experiments, on its nonconductivity.

To sum up: It has been advanced that the fact that stannic chloride is homogeneous, chemically homogeneous, accounts for its nonconductivity : similarly for the other nonelectrolytes. To continue : It will be demonstrated how the results obtained show that where this chemical homogeneity is destroyed, where the whole or part of the stannic chloride enters into combination so that molecular interchanges, akin to those which Williamson so vividly portrayed in his epoch-making papers on the Theory of Etherification, can occur, then the power of electrolytic conductivity is developed. The validity of this conclusion will be most cogently established by answer-

* Report on the Present State of our Knowledge in Electrolysis and in Electrochemistry. W. N. Shaw, M.A. (Brit. Assoc. 1889).

$\dagger$ Pogg. Ann. 1876, p. 159.

† Kongl.Vetenskaps-Akad. Fordhandlingar, 1885. 
ing the following question: Whereas hydrochloric-acid gas, alcohol, ether, aqueous hydrochloric acid, sulphuretted hydrogen and alcohol, render stannic chloride an electrolysable liquid, why do not chlorine, sulphuretted hydrogen, chloroform, the various solids mentioned in Part I., exert a similar influence?

The answer is, that the former enter into chemical combination, the latter do not. To quote the concluding sentence of Part I., the latter class of substances "producing no effect on the chemical homogeneity of the stannic chloride, which remains merely stannic chloride, are without influence on its electrical conductivity :" a collection of unit particles, $\mathrm{SnCl}_{4}$, even where mechanically interspersed with foreign substances, do not conduct. But when hydrochloric-acid gas, alcohol, ether, hydrochloric-acid solution, sulphuretted hydrogen and alcohol, are added, electrolytic power is developed. Here, however, there is no longer chemical homogeneity.

The stannic chloride charged with hydrochloric-acid gas must contain a collection of molecules of the double chloride $2 \mathrm{HCl}$. SnCl 4 interspersed amongst molecules of stannic chloride. There is here manifestly the potentiality of a continual condition of interchange between the combined and uncombined stannic-chloride molecules; a condition of dynamical equilibrium maintained by changes of this nature :-

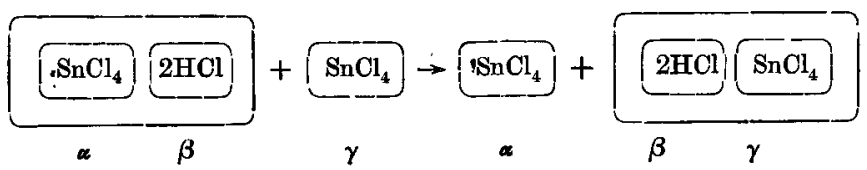

The similar phenomenon is repeated under the influence of absolute alcohol; here the alcoholate $\mathrm{SnCl}_{4} \cdot 2 \mathrm{C}_{2} \mathrm{H}_{5} \mathrm{OH}$ is formed and dissolved in the excess of alcohol. The equilibrium would depend on, here, the interchange of the combined alcohol molecules for the uncombined:-

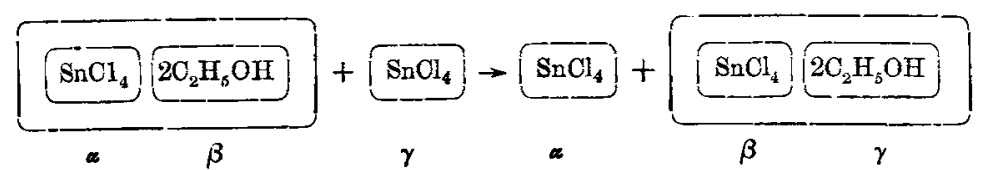

Similarly for the etherate $\mathrm{SnCl}_{4}, 2\left(\mathrm{C}_{2} \mathrm{H}_{5}\right)_{2} \mathrm{O}:-$

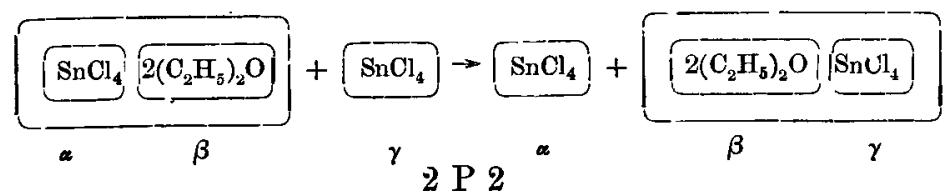


The idea of examining the influence of these liquids proceeded from a study of Moissan's* work on liquid hydrofluoric acid; it seemed that the conductivity he developed was due to such -an interchange as :-

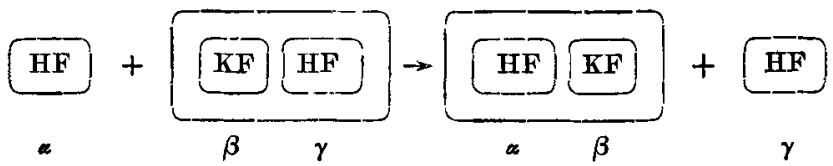

and it was conceived that if a similar condition of dynamical stability could be produced in stannic chloride, conductivity would be developed. The results have justified the induction. The delicate observations made by Kohlrausch on the resistance of pure water, and the effect of exposing it to the atmosphere of a room charged with tobacco-smoke, are explicable on the same lines; the water would absorb traces of carbonic acid and of the basic products, which in turn would form hydrates, and then there would result a similar condition of interchange.

The generalization may now be provisionally stated:-that such an antecedent condition of dynamical equilibrium is absolutely essential to the development of the power of electrolytic conductivity. With no great difficulty, it would be possible in terms of

(1) the number of such interchanges per unit of time,

(2) the degree to which the stability of the original unelectrolysable molecule is disturbed by each interchange, to establish a dynamical theory to explain the influence of $(a)$ the concentration, $(b)$ the temperature, on the conductivity of electrolytes; and for this purpose would be needed accurate measurements of the resistance of solutions (say, of the tetrachloride in alcohol, in ether, and of their temperature-coefficients). The results would emphasize the great value of some dynamical explanation of chemical action, and the influence of mass and temperature on its course.

The differences observed in the action of

(1) dry sulphuretted hydrogen on stannic chloride,

(2) dry sulphuretted hydrogen on stannic chloride in chloroform solution,

(3) dry sulphuretted hydrogen and stannic chloride on water,

(4) absolute alcohol on sulphuretted bydrogen and stannic chloride,

(5) dry sulphuretted hydrogen on ether and stannic chloride,

* An account of Moissan's work is given in 'Nature,' vol. xxxvii. (1887-8); Moissan considers the potassium fluoride to be the electrolyte. 
cannot fail to be suggestive. At present it may be noted that "where there exists an aptitude for directed decomposition," such as is involved in the above dynamical conc sptic $n$, and such as exists in the aqueous or alcoholic solution of stannic chloride, there sulphuretted hydrogen at once precipitates stannic sulphide; whereas between the dry sulphuretted hydrogen and stannic chloride there is found only a small quantity of addition compound $\left(\mathrm{SnCl}_{4}, 5 \mathrm{H}_{2} \mathrm{~S}\right)$, which, when agitated into a condition of instability by elevation of temperature, gives the stannic sulphide observed by Dumas. This influence of alcohol on stannic chloride and sulphuretted hydrogen is typical of that of catalytic agents in general; and the explanation here suggested is of wide application. The phenomena discovered by Prof. Dixon, to whom I am indebted for a complete list of the published papers on the action of dry substances, are of a parallel nature. He found that the combination of dry carbon monoxide and dry oxygen,

$$
2 \mathrm{CO}+\mathrm{O}_{2}=2 \mathrm{CO}_{2}{ }^{*} \text {, }
$$

occurs only in the path of the spark, but that when the gases are moist the combination is explosive. Again, Dixon has shown that, in the combustion of carbonic oxide and hydrogen, the influence of the steam is not of a physical but of a chemical nature $\dagger$. The inactivity of dry hydrochloric acid and dry oxygen, of dry hydrobromic acid and dry oxygen, and their activity in the presence of water is of the same nature (Richardson). The observation, made by Pringsheim $\$$, that dry chlorine and dry hydrogen do not combine in sunlight, but that the presence of a small quantity of water is sufficient to determine their combination, is quite parallel. Baker has proved that some dry solids are incombustible in dry oxygen, though he finds that others are combustible $\|$.

It cannot be maintained as a law of nature that no two pure substances, $A B, D C$, combine ; either

(1) $\mathrm{AB}+\mathrm{DC}=\mathrm{AB} \cdot \mathrm{DC}$,

(2) $\mathrm{AB}+\mathrm{DC}=\mathrm{AD}+\mathrm{BC}$,

possibly passing through the stage

$$
A B . D C \rightarrow A D+B C .
$$

As an example of such a change, we have

$$
\begin{aligned}
& \mathrm{SnCl}_{4}+5 \mathrm{H}_{2} \mathrm{~S}=\mathrm{SnCl}_{4} .5 \mathrm{H}_{2} \mathrm{~S}, \\
& \mathrm{SnCl}_{4} 5 \mathrm{H}_{2} \mathrm{~S} \rightarrow \mathrm{SnS}_{2}+4 \mathrm{HCl}+3 \mathrm{H}_{2} \mathrm{~S} ;
\end{aligned}
$$

* Phil. Trans. 1884.

$\ddagger$ Journ. Chem. Soc. li. p. 803.

il Phil. Trans. 1888, "A."
+ Journ. Chem. Soc. 1886 , p. 94.

$\$$ Wied. Ann. xxxii. p. 384. 
but here, as in all the above cases, the catalytic agent, by producing a condition of dynamical equilibrium, greatly facilitates the change.

Further instances of the precise similarity between the action of catalytic agents and of those substances which are capable of endowing nonconducting liquids with the power of conduction will doubtless be found, and further proof analogous to those advanced here in the case of stannic chloride of the strict parallelism between the phenomena, of the birth of electrolytic power and of enhanced chemical activity, will trace these effects back to an identity of cause, the setting up of a condition of dynamical equilibrium.

Emmanuel College, Cambridge.

LVI. The Theory of Osmotic Pressure and its bearing on the Nature of Solutions. By Spencer Umfreville Pickerdng, M.A.*

NO one can doubt the mathematical correctness of the conclusions which Arrhenius,'van't Hoff, Ostwald, and others draw from the premisses with which they start in their arguments respecting osmotic pressure, nor can we doubt the value of connecting numerous actions with one and the same cause, or that there are a large number of instances in which the observed facts are in substantial agreement with their conclusions. But we may, I think, legitimately doubt whether the premisses of the arguments are sound, whether the conclusions harmonize as well as they should with experimental data, whether the theory is more than a mathematical exercise, or more than a convenient working hypothesis of a rough character, instead of being, as its supporters maintain, an hypothesis established so firmly that we may build upon it a physical theory of solution.

The direct measurement of osmotic pressure has been made in but a few cases, and those cases are ones in which the substances examined are eminently unfitted for showing the presence of any chemical action which may be present. Of the phenomena correlated with osmotic pressure, the lowering of the freezing-point of a solvent by the addition of foreign substances is the one which has received the greatest attention, thanks to Raoult's classical work, and is the one which forms the main support of the theory.

In examining the experimental facts the following questions must be asked, and if the theory is correct they must be answered in the affirmative.

* Communicated by the Physical Society: read Mareh 7, 1890. 